\title{
No differences in return of pain-related fear after extinction and counterconditioning
}

Citation for published version (APA):

Gatzounis, R., De Bruyn, S., Van de Velde, L., \& Meulders, A. (2022). No differences in return of painrelated fear after extinction and counterconditioning. Emotion, 22(8), 1886-1894. https://doi.org/10.1037/emo0000960

Document status and date:

Published: 01/12/2022

DOI:

10.1037/emo0000960

Document Version:

Publisher's PDF, also known as Version of record

Document license:

Taverne

Please check the document version of this publication:

- A submitted manuscript is the version of the article upon submission and before peer-review. There can be important differences between the submitted version and the official published version of record.

People interested in the research are advised to contact the author for the final version of the publication, or visit the DOI to the publisher's website.

- The final author version and the galley proof are versions of the publication after peer review.

- The final published version features the final layout of the paper including the volume, issue and page numbers.

Link to publication

\footnotetext{
General rights rights.

- You may freely distribute the URL identifying the publication in the public portal. please follow below link for the End User Agreement:

www.umlib.nl/taverne-license

Take down policy

If you believe that this document breaches copyright please contact us at:

repository@maastrichtuniversity.nl

providing details and we will investigate your claim.
}

Copyright and moral rights for the publications made accessible in the public portal are retained by the authors and/or other copyright owners and it is a condition of accessing publications that users recognise and abide by the legal requirements associated with these

- Users may download and print one copy of any publication from the public portal for the purpose of private study or research.

- You may not further distribute the material or use it for any profit-making activity or commercial gain

If the publication is distributed under the terms of Article $25 \mathrm{fa}$ of the Dutch Copyright Act, indicated by the "Taverne" license above, 


\section{Emotion}

\section{No Differences in Return of Pain-Related Fear After Extinction and}

Counterconditioning

Rena Gatzounis, Sofie De Bruyn, Liselot Van de Velde, and Ann Meulders

Online First Publication, June 17, 2021. http://dx.doi.org/10.1037/emo0000960

\section{CITATION}

Gatzounis, R., De Bruyn, S., Van de Velde, L., \& Meulders, A. (2021, June 17). No Differences in Return of Pain-Related Fear After Extinction and Counterconditioning. Emotion. Advance online publication. http://dx.doi.org/10.1037/emo0000960 


\title{
No Differences in Return of Pain-Related Fear After Extinction and Counterconditioning
}

\author{
Rena Gatzounis ${ }^{1}$, Sofie De Bruyn ${ }^{2}$, Liselot Van de Velde ${ }^{2}$, and Ann Meulders ${ }^{1,2}$ \\ ${ }^{1}$ Experimental Health Psychology, Department of Clinical Psychological Science, Maastricht University \\ ${ }^{2}$ Research Group on Health Psychology, Faculty of Psychology and Educational Sciences, KU Leuven
}

\begin{abstract}
Extinction-based protocols such as exposure-in-vivo successfully reduce pain-related fear in chronic pain conditions, but return of fear and clinical relapse often occur. Counterconditioning is assumed to attenuate return of fear, likely through changing the negative affective valence of the conditioned stimulus (CS). We hypothesized that counterconditioning would outperform extinction in mitigating return of pain-related fear and decrease CS negative affective valence. Healthy participants performed a conditioning task, in which 2 joystick movements (CSs+) were paired with a painful electrocutaneous stimulus (unconditioned stimulus; pain-US), whereas 2 other movements (CSs-) were not. Subsequently, in the extinction group, $1 \mathrm{CS}+$ was extinguished (pain-US omission) and the other not, whereas in the counterconditioning group, $1 \mathrm{CS}+$ was presented with a US of opposite valence (reward-US) and the other was paired with both USs. We tested reinstatement of pain-related fear after 2 unsignalled painUS presentations. Results showed no group differences in fear reduction and no differences in CS affective valence changes between the extinguished and counterconditioned CS. Remarkably, none of the groups showed reinstatement. Overall, counterconditioning did not appear to be more effective than extinction in reducing pain-related fear and its return.
\end{abstract}

Keywords: extinction, counterconditioning, pain-related fear, reinstatement, return of fear

Supplemental materials: https://doi.org/10.1037/emo0000960.supp

Ample evidence confirms that fear of movement-related pain can be acquired through classical conditioning (Meulders, 2020). As a salient biological warning signal, pain can be considered an unconditioned stimulus (US) eliciting protective responses (e.g., fear and escape; Meulders, 2020; Vlaeyen, 2015). After (repeated) pairings with pain, initially neutral movements (conditioned stimuli; CSs) may come to signal pain and elicit fear themselves (conditioned response; CR; Meulders, 2020). Learning to predict pain is adaptive and enables one to take protective action, but when pain becomes chronic, continued fear and avoidance may compromise daily functioning (Vlaeyen, 2015).

Subsequently, conditioned fear of movement-related pain can be reduced using Pavlovian extinction, that is, presenting the $\mathrm{CS}+$ without the pain-US (Meulders, 2020). Exposure-in-vivo is the

Rena Gatzounis (D) https://orcid.org/0000-0002-7058-6671

This research was supported by a Senior Research Fellowship of the Research Foundation Flanders (FWO-Vlaanderen), Belgium (grant ID: $12 \mathrm{E} 3717 \mathrm{~N}$ ), and a Vidi Grant from the Netherlands Organization for Scientific Research (NWO), the Netherlands (grant ID 452-17-002), both granted to Ann Meulders. The authors have no conflict of interest to report.

Correspondence concerning this article should be addressed to Ann Meulders, Experimental Health Psychology, Department of Clinical Psychological Science, Maastricht University, Universiteitssingel 40, 6229 ER Maastricht, the Netherlands. Email: ann.meulders@maastricht university.nl clinical analogue of extinction (Vervliet et al., 2013), and the gold standard to tackle catastrophic harm expectancies that underlie chronic pain disability (e.g., if I lift a crate, my spine will snap; den Hollander et al., 2010). Exposure has been proven effective for chronic pain (e.g., Glombiewski et al., 2018), but relapse often occurs, leaving room for improvement.

Full-blown relapse may follow the postextinction return of fear (Bouton, 2002; Vervliet et al., 2013). Contemporary learning theory conceptualizes extinction not as "unlearning" the original CS-US association, but as learning a new (CS-noUS) association that inhibits the retrieval and behavioral expression of the former (Bouton, 2002). Extinction is context-dependent and therefore fragile; release from inhibition may thus lead to return of fear (Bouton, 2002). Unexpected encounters with the US, for example, when a person with chronic pain experiences a pain flare-up after successful treatment, is one mechanism that may make fear reemerge (reinstatement; Bouton, 2002; Haaker et al., 2014; Meulders, 2020).

An alternative procedure to reduce fear is counterconditioning, which involves pairing the CS+ with a US of opposite valence (Keller et al., 2020). Counterconditioning is thought not only to reduce US-expectancy, but also change the CS affective valence (Engelhard et al., 2014; Hermans et al., 2002). Residual CS negative valence presumably underlies the return of fear (Dirikx et al., 2004). Therefore, reducing CS negative valence may also reduce return of fear. There is some experimental evidence for attenuated 
return of fear after counterconditioning compared to extinction (Kang et al., 2018) though opposite findings have also been reported (van Dis et al., 2019).

One study to date has compared extinction and counterconditioning in reducing fear of movement-related pain (Meulders et al., 2015). In that study, participants performed a conditioning task, in which two joystick movements (CSs+) were associated with the pain-US, whereas two others (CSs-) were not. Subsequently, one CS + was extinguished, that is, the pain-US was omitted, or counterconditioned, that is, followed by monetary reward (between-subjects). No differences between extinction and counterconditioning were observed at immediate test, but the authors suggested that such differences may manifest after return of fear manipulations (cf. Dirikx et al., 2004; Kang et al., 2018) Therefore, the present study aimed to compare reinstatement of fear of movement-related pain after extinction and counterconditioning. Using an adjusted version of the Voluntary Joystick Movement paradigm of Meulders and colleagues (2015) we tested whether counterconditioning would generate (a) less reinstatement of fear of movement-related pain, and (b) larger decrease in CS negative valence compared to extinction.

\section{Method}

\section{Participants}

Seventy-four healthy adults were randomly allocated to the Extinction (EXT; $n=39$ ) or the Counterconditioning (COUNTER; $n=35$ ) group. Sample size was larger compared to the previous study of Meulders et al. (2015), in order to account for the additional experimental phase of reinstatement, and sufficed for the detection of a moderate-to-large effect, as calculated with G*Power 3.1.9.2 (Faul et al., 2007). Six participants were excluded (5 due to technical problems, 1 was later revealed to meet exclusion criteria), leaving 68 participants (EXT: $n=36$; COUNTER: $n=32$ ) for statistical analyses. Participants were recruited via the KU Leuven online recruitment system, advertisements, and word-of-mouth. Exclusion criteria were pregnancy; acute pain or impairment at the dominant hand/wrist; presence of cardiac pacemaker or other medical device; uncorrected hearing problems; past or current severe medical conditions, psychiatric disorders, or chronic pain; and medical advice to avoid stressful situations. The Social and Societal Ethics Committee of the KU Leuven approved the study protocol (G-201512426).

\section{Stimulus Material}

Conditioned stimuli (CSs) were four proprioceptive stimuli, namely moving an Attack 3 Joystick (Logitech International S.A., Lausanne, Switzerland) upward, downward, to the left, and to the right. One movement in the vertical plane and one in the horizontal plane were the CSs + (counterbalanced across participants). The other movements were the CSs-. The painful unconditioned stimulus (pain-US) was a 2-ms square-wave electrocutaneous stimulus generated by a DS7A constant current stimulator (Digitimer Limited, Hertfordshire, United Kingdom) and delivered on the dominant wrist via two $0.8 \mathrm{~mm} \mathrm{Ag} / \mathrm{AgCl}$ surface electrodes (SensorMedics Corp., Yorba Linda, CA) filled with K-Y gel (Johnson \& Johnson, New Brunswick, NJ). Pain-US intensity was individually calibrated to be "significantly painful and demanding some effort to tolerate", according to the procedure of Meulders et al. (2015). The mean physical intensity was $31.1 \mathrm{~mA}(S D=20.6$, range $=8.0-99.9)$, and corresponded to a self-reported intensity of $8.1(S D=.3,8-9)$ on the $0-10$ pain calibration scale. There were no Group differences in either the physical, $F(1,66)=.13, p=.724$, or the self-reported pain-US intensity, $F(1,66)=1.06, p=.308$, as these were rated at the end of the calibration phase. The reward-US was an image of two lottery tickets, increasing the chance to win a prize of approximate value of $€ 100$. At the start of the study, participants were told that they had already received ten lottery tickets merely by participating, but that they would have the opportunity to win more lottery tickets throughout the experiment, thus increasing their chance of winning. To increase reward-US motivation, participants selected their prize of choice from a preset list (cf. Claes et al., 2016; Claes et al., 2015).

\section{Measures}

We assessed fear of movement-related pain by asking "To what extent were you afraid to perform the left/right/upward/downward movement?," and pain-US expectancy by asking "To what extent did you expect an electrical stimulus when you moved the joystick to the left/right/upward/downward?." Participants responded on an 11-point Likert scale ranging from "not at all" to "very much." Furthermore, we assessed CS valence with the affective valence subscale of the Self-Assessment Manikin (Bradley \& Lang, 1994) scale, accompanied by the question "How did you feel during moving the joystick to the left/right/upward/downward?." Participants responded on the 5-point scale, with anchors "very happy" and "very unhappy," and the middle point labeled as "neutral." As a manipulation check, we assessed reward-US expectancy with the question "To what extent did you expect a lottery ticket when moving the joystick to the left/right/upward/downward?," on an 11-point Likert scale ranging from "not at all" to "very much." Participants rated fear of movement-related pain, pain-US and reward-US expectancy at the end of each block of 16 trials, and CS valence at the end of each experimental phase (see "Procedure"). Furthermore, participants filled in online (LimeSurvey Project Team \& Schmitz, 2012) a series of psychological trait questionnaires assessing fear of pain (Fear of Pain Questionnaire-III; McNeil \& Rainwater, 1998; Roelofs et al., 2005); pain catastrophizing (Pain Catastrophizing Scale; Sullivan et al., 1995; Van Damme et al., 2002); positive and negative affect (Positive and Negative Affect Schedule; Engelen et al., 2006; Watson et al., 1988); and trait anxiety (State-Trait Anxiety Inventory, trait version; Spielberger, 1983; Van der Ploeg, 1980), to map potential Group differences and ensure successful randomization.

\section{Procedure}

Participants performed an adapted version of the Voluntary Joystick Movement (VJM) task (see Figure 1) used by Meulders et al. (2015), with the following methodological improvements. First, we used a partial reinforcement schedule, preventing rapid extinction, likely allowing potential differences in the speed or magnitude of fear reduction to materialize. Second, we used a personally relevant reward-US, in order to increase its motivational value. Third, we assessed CS valence more frequently, in order to gain a 
Figure 1

Overview of an Illustrative Trial in (A) the Fear Acquisition Phase, and the Fear Reduction Phase in (B) the EXT Group and (C) the COUNTER Group
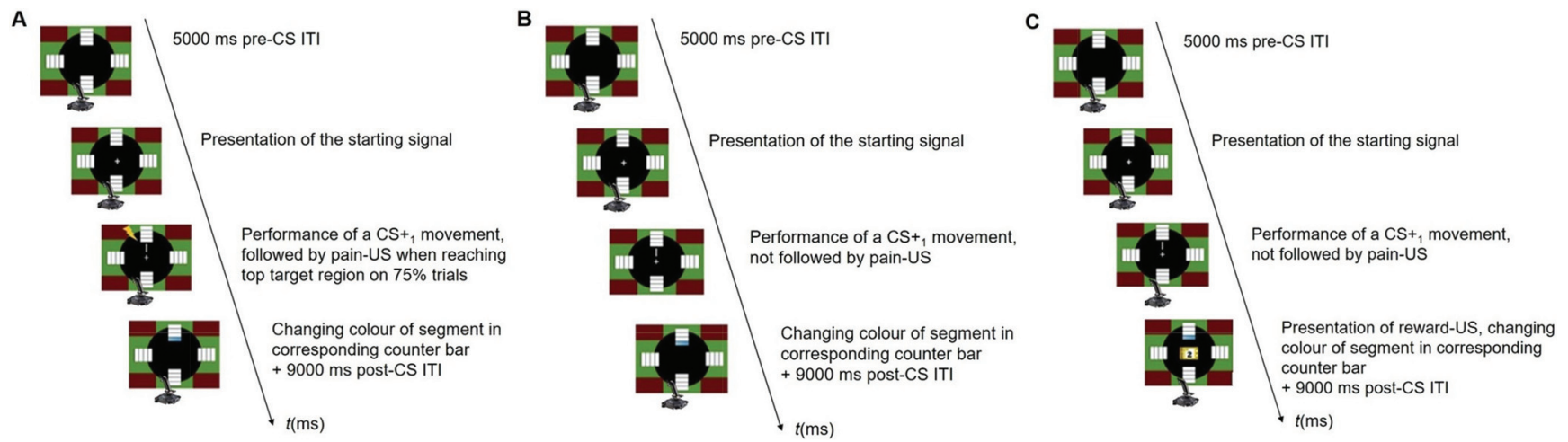

Note. The white cross represents the starting signal of the trial, the white arrow represents the direction of the joystick movement, the lightning bolt represents the pain-US, the yellow rectangle represents the reward-US, and the blue segment of the counter bar indicates that a movement in the corresponding direction was completed. The valid and invalid movement regions are illustrated by the green and red areas, respectively; note that these were visible to the participants only during the practice phase. During the fear acquisition phase (A), participants received a pain-US on $75 \%$ of the times that they performed a $\mathrm{CS}+_{1}$ or $\mathrm{CS}+_{2}$ movement. The fear acquisition phase was identical for both groups. During the fear reduction phase in the EXT group, the $\mathrm{CS}+_{1}$ movement was extinguished, i.e. not paired with a pain-US (B), whereas the $\mathrm{CS}_{2}$ continued to be paired with the pain-US. During the fear reduction phase in the COUNTER group, the $\mathrm{CS}+_{1}$ movement was counterconditioned, i.e. paired with a reward-US $(\mathrm{C})$, whereas the CS $+_{2}$ was paired with both the reward-US and the pain-US. See the online article for the color version of this figure.

better understanding of its changes across time. The task consisted of the following phases: practice, fear acquisition, fear reduction, reinstatement, and test.

Participants were told that the experiment regarded the effects of distractors on motor performance, and were tested individually in a session lasting approximately $2 \mathrm{hr}$. The lab session also included assessments of inhibitory capacity, in the context of a separate research question not further discussed. For the part that is of interest here, exclusion criteria were checked by means of self-report and participants provided informed consent. Subsequently, the experimenter attached electrodes for the administration of the pain-US and the measurement of the eyeblink startle reflex. Due to technical problems that rendered the startle measurement unreliable, however, we omit it from the description of the procedure and results.

\section{Pain-US and Reward-US Selection}

The pain-US intensity was individually determined (see "Stimulus Material"), and participants selected their preferred prize from a preset list. Participants received 10 lottery tickets at the start of the experiment. Although only COUNTER Group participants received additional lottery tickets during the experiment, in reality this did not affect their chance of winning (cf. Claes et al., 2015).

\section{Practice}

To get familiarized with the task, participants performed 16 joystick movements (4 in each direction). A counter bar divided into four segments was presented at each of four locations (top, bottom, left and right) on a black background, providing visual feedback about the number of movements participants were required to perform in each direction (upward, downward, to the left and to the right, respectively). Each trial began with a pre-CS intertrial interval (ITI) of $5000 \mathrm{~ms}$, followed by a white cross presented in the middle of the screen, probing the start of the joystick movement. Participants moved as fast and accurately as possible, in the direction of their choice. The cross remained on the screen until movement onset. Upon movement completion, one of the counter bar segments at the corresponding location turned blue, and a post-CS ITI of 5000ms started. During practice, performance feedback was provided. First, the joystick cursor was shown, visualizing the movement. Second, the valid movement regions were colored green, whereas the invalid ones were colored red. Third, the experimenter provided oral feedback. No pain-US or rewardUS was presented.

\section{Fear Acquisition}

This phase ( 3 blocks of 4 movements in each direction) was the same as practice, apart from the following. First, two movements (one in the horizontal and one in the vertical plane; counterbalanced) were followed by a pain-US, thus serving as $\mathrm{CSs}+\left(\mathrm{CS}+{ }_{1}\right.$ and $\mathrm{CS}+{ }_{2}$ ). The pain-US was administered upon movement offset on $75 \%$ of CSs + trials. The other two movements were never followed by a pain-US, thus serving as $\mathrm{CSs}-\left(\mathrm{CS}-{ }_{1}\right.$ and $\left.\mathrm{CS}-{ }_{2}\right)$. The $\mathrm{CS}-{ }_{1}$ was in the same movement plane as $\mathrm{CS}+{ }_{1}$, whereas the $\mathrm{CS}-{ }_{2}$ was in the same movement plane as the $\mathrm{CS}+{ }_{2}$. Second, there was a pre-CS ITI of $5000 \mathrm{~ms}$ and a post-CS ITI of $9000 \mathrm{~ms}$.

\section{Fear Reduction}

This phase comprised 4 blocks of 4 movements in each direction, differing for the two groups. For the EXT group, one CS+ was extinguished (i.e., pain-US omitted; $\mathrm{CS}+{ }_{1}$ ), whereas the other one $\left(\mathrm{CS}+{ }_{2}\right)$ remained $75 \%$ reinforced. For the COUNTER group, one CS+ was counterconditioned (i.e., $75 \%$ reinforced with the reward-US; $\left.\mathrm{CS}+{ }_{1}\right)$, whereas the other one $\left(\mathrm{CS}+{ }_{2}\right)$ was followed by both USs on $75 \%$ of the trials. $\mathrm{CS}-{ }_{1}$ and $\mathrm{CS}-{ }_{2}$ were never reinforced. 


\section{Reinstatement}

On the 2000th and the 12000th ms of the first ITI after fear reduction, and while the counter bars were still visible, participants received two unsignalled pain-USs. No joystick movements were made during this phase (total duration $=14000 \mathrm{~ms}$ ).

\section{Test}

Participants performed 4 movements in each direction, with the same reinforcement schedule as during fear reduction.

After the VJM task, participants completed the psychological trait questionnaires and were debriefed about the lottery manipulation. Full debriefing occurred upon completion of data collection.

\section{Statistical Analyses}

For sample characteristics, we computed descriptive statistics and compared the two groups by means of a series of ANOVAs and $\chi^{2}$-tests. For manipulation checks, we report planned contrasts on reward-US expectancy, and fear acquisition and reduction, which are prerequisites to investigate return of fear. We also report planned contrasts for our main hypotheses that counterconditioning reduces (1) differential fear reinstatement, and (2) negative CS valence compared to extinction. To correct for multiple testing, we applied Holm-Bonferroni correction.

For the sake of completeness, we also performed a series of Repeated Measures (RM) ANOVAs with Group as between-subjects factor, and block and stimulus as within-subjects factors. The full ANOVA results are in line with these of the planned contrasts, and can be found in the online supplemental material. Analyses were performed with SPSS 24.0 (IBM, Armonk, NY: IBM Corp).

\section{Results}

\section{Sample Characteristics}

The two groups did not differ in sex ratio, mean age, or mean questionnaire scores (see Table 1).

\section{Manipulation Checks}

\section{Reward-US Expectancy}

Figure 2 indicates that the COUNTER Group expected the reward-US more for the CSs+ and less for the CSs-, whereas the
EXT Group reported low reward-US expectancies for all CSs throughout the fear reduction phase. Planned comparisons confirmed that at the end of the reduction phase, COUNTER Group participants expected a reward-US more than the EXT Group participants after the two CSs that were indeed followed by the reward-US, that is, the $\mathrm{CS}+{ }_{1}, \Delta_{\mathrm{CS}+1}$ at RED4(COUNTER-EXT) $=5.8$, $95 \%$ CI $[4.7,7.0], t(65.72)=10.25, p<.001$, and the $\mathrm{CS}+{ }_{2}$, $\Delta_{\mathrm{CS}+2 \text { at RED4(COUNTER-EXT) }}=5.8,95 \%$ CI $[4.5,7.1], t(48.02)=$ 8.87, $p<.001$. As expected, the two groups reported similar reward-US expectancy for the $\mathrm{CS}-{ }_{1}, \Delta_{\mathrm{CS}-1}$ at RED4(COUNTER-EXT) $=-1.0,95 \%$ CI $[-2.05, .04], t(58.85)=-1.92, p=.60$, and the $\mathrm{CS}-{ }_{2}, \Delta_{\mathrm{CS}-2}$ at RED4(COUNTER-EXT) $=-.2,95 \% \mathrm{CI}[-1.3,1.0]$, $t(66)=-.28, p=.780$. Thus, COUNTER, but not EXT, participants expected a reward-US after the $\mathrm{CSs}+$, indicating that our manipulation was successful.

\section{Fear Acquisition}

Figure 3 suggests that throughout the acquisition phase, fear of movement-related pain and pain-US expectancy increased for the two CSs +, but remained stably low for the two CSs-. For fear of movement-related pain (Figure 3a), planned contrasts confirmed that, at the end of the acquisition phase, participants of both groups were more afraid of $\mathrm{CS}+{ }_{1}$ compared to the $\mathrm{CS}-{ }_{1}$, EXT: $\Delta_{\mathrm{CS}+1-\mathrm{CS}-1}=3.0,95 \%$ CI $[2.0,4.0], t(35)=6.02, p<.001$; COUNTER: $\Delta_{\mathrm{CS}+1-\mathrm{CS}-1}=2.5,95 \%$ CI $[1.4,3.6], t(31)=4.57, p<$ .001 . In addition, both groups reported more fear for the $\mathrm{CS}+2$ compared to $\mathrm{CS}{ }_{-2}$, EXT: $\Delta_{\mathrm{CS}+2-\mathrm{CS}-2}=2.0,95 \%$ CI $[.6,3.4]$, $t(35)=2.98, p=.005$; COUNTER: $\Delta_{\mathrm{CS}+2-\mathrm{CS}-2}=1.9,95 \%$ CI $[.4$, 3.5], $t(31)=2.59, p=.015$. In both groups, however, participants were similarly afraid of the two CSs+, EXT: $\Delta_{\mathrm{CS}+1-\mathrm{CS}+2}=.4,95 \%$ CI $[-.7,1.5], t(35)=.73, p=.470$; COUNTER: $\Delta_{\mathrm{CS}+1-\mathrm{CS}+2}=.1$, $95 \%$ CI $[-.6, .9], t(31)=.34, p=.739$. Similar planned contrasts on the pain-US expectancy ratings (Figure $3 \mathrm{~b}$ ) indicated that at the end of the acquisition phase, participants of both groups expected pain to occur more after $\mathrm{CS}+{ }_{1}$ compared to $\mathrm{CS}-{ }_{1}$, EXT: $\Delta_{\mathrm{CS}+1-\mathrm{CS}-1}=6.1$, 95\% CI $[4.6,7.5], t(35)=8.7, p<.001$; COUNTER: $\Delta_{\mathrm{CS}+1-\mathrm{CS}-1}=$ $5.7,95 \%$ CI $[4.3,7.1], t(31)=8.3, p<.001$, and after $\mathrm{CS}+{ }_{2}$ compared to $\mathrm{CS}-{ }_{2}$, EXT: $\Delta_{\mathrm{CS}+2-\mathrm{CS}-2}=6.4,95 \%$ CI $[5.1,7.7], t(35)=$ 10.2, $p<.001$; COUNTER: $\Delta_{\mathrm{CS}+2-\mathrm{CS}-2}=5.0,95 \%$ CI $[3.5,6.5]$, $t(31)=6.9, p<.001$. Both groups, however, expected pain after the two CSs + to a similar degree, EXT: $\Delta_{\mathrm{CS}+1-\mathrm{CS}+2}=-.5,95 \% \mathrm{CI}$ $[-1.1, .1], t(35)=-1.6, p=.127$; COUNTER: $\Delta_{\mathrm{CS}+1-\mathrm{CS}+2}=.5$, $95 \%$ CI $[-.1,1.2], t(31)=1.6, p=.117$. Taken together, these

\section{Table 1}

Sex Ratio, Age, and Psychological Trait Questionnaire Scores (M, With SD and Range in Parentheses) Separately Per Group, and Group Comparisons

\begin{tabular}{|c|c|c|c|}
\hline Characteristic & $\begin{array}{l}\text { Extinction group } \\
\quad(n=36)\end{array}$ & $\begin{array}{l}\text { Counterconditioning group } \\
\qquad(n=32)\end{array}$ & Comparison \\
\hline Women: Men & 26: 10 & $25: 7$ & $\chi^{2}(1)=0.32, p=.575$ \\
\hline Age & $21.2(3.7,18-37)$ & $21.8(7.2,18-59)$ & $F(1,66)=0.21, p=.651$ \\
\hline Pain catastrophizing (PCS) & $16.1(6.6,4.0-30.0)$ & $17.6(7.7,4.0-34.0)$ & $F(1,66)=0.72, p=.398$ \\
\hline Fear of pain (FPQ) & $68.7(11.9,39.0-92.0)$ & $68.1(13.9,47.0-97.0)$ & $F(1,66)=.04, p=.848$ \\
\hline Negative affect (PANAS) & $18.9(5.4,10.0-32.0)$ & $20.8(6.5,12.0-36.0)$ & $F(1,66)=1.73, p=.194$ \\
\hline Positive affect (PANAS) & $34.7(5.1,21.0-45.0)$ & $34.8(6.0,24.0-45.0)$ & $F(1,66)=0.01, p=.930$ \\
\hline Trait anxiety (STAI) & $37.6(8.4,22.0-55.0)$ & $39.6(9.1,24.0-62.0)$ & $F(1,65)=0.93, p=.339$ \\
\hline
\end{tabular}

Note. $\quad$ PCS = Pain Catastrophizing Scale; FPQ = Fear of Pain Questionnaire; PANAS = Positive and Negative Affect Schedule; STAI = State-Trait Anxiety Inventory. 
Figure 2

Reward-US Expectancy Ratings From the End of Acquisition (ACQ) to the End of Fear Reduction (RED), Separately Per Group

\section{Reward-US expectancy}

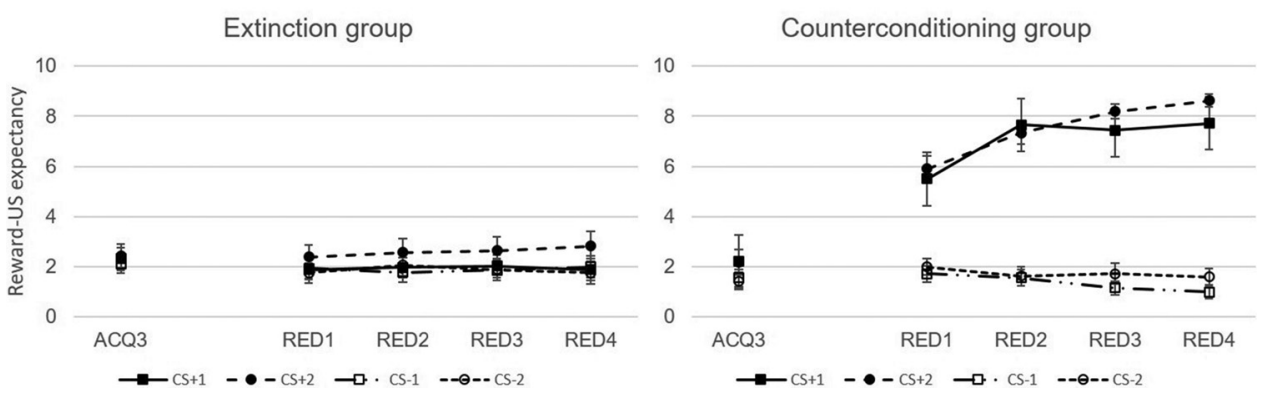

Note. Error bars denote standard errors.

findings confirm that differential fear acquisition occurred successfully in both groups.

\section{Fear Reduction}

Figure 3 suggests that, throughout the fear reduction phase, fear of movement-related pain and pain-US expectancy for the CS+ that was extinguished or counterconditioned $\left(\mathrm{CS}+{ }_{1}\right)$ steadily decreased, whereas for the movement that was still paired with pain $(\mathrm{CS}+2)$ remained stably high or even slightly increased. Planned contrasts confirmed that, from the end of the acquisition phase to the end of the reduction phase, fear of movement-related pain (Figure 3a) reduced more for $\mathrm{CS}+{ }_{1}$ than for $\mathrm{CS}+{ }_{2}$. This was the case for both groups, EXT: $\Delta_{(\mathrm{CS}+1}$ at ACQ3-CS+1 at RED4)-(CS+2 at ACQ3-CS +2 at RED4) $=3.6,95 \%$ CI $[2.4,4.7], t(35)=6.37, p<$ .001 ; COUNTER: $\Delta_{(\mathrm{CS}+1}$ at ACQ3-CS +1 at RED4)-(CS+2 at ACQ3-CS+2 at RED4) $=3.3,95 \%$ CI $[2.3,4.3], t(31)=6.93, p<.001$. Furthermore, in both groups the reduction was greater for the extinguished or counterconditioned movement, compared to its counterpart CS-, EXT: $\Delta_{(\mathrm{CS}+1}$ at ACQ3-CS +1 at RED4)-(CS-1 at ACQ3$\mathrm{CS}-1$ at RED4) $=2.8,95 \%$ CI $[1.4,4.1], t(35)=4.07, p<.001$;

Figure 3

Fear of Movement-Related Pain (Panel a) and Pain-US Expectancy (Panel b) Ratings During the Acquisition (ACQ), Fear Reduction (RED), and Test (TEST) Phases, Separately Per Group

\section{a. Fear of movement-related pain}
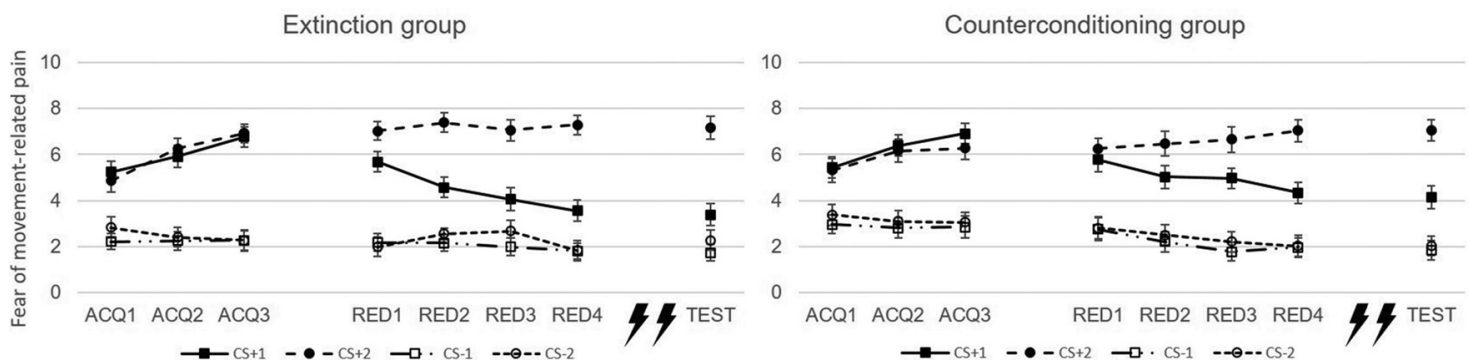

b. Pain-US expectancy
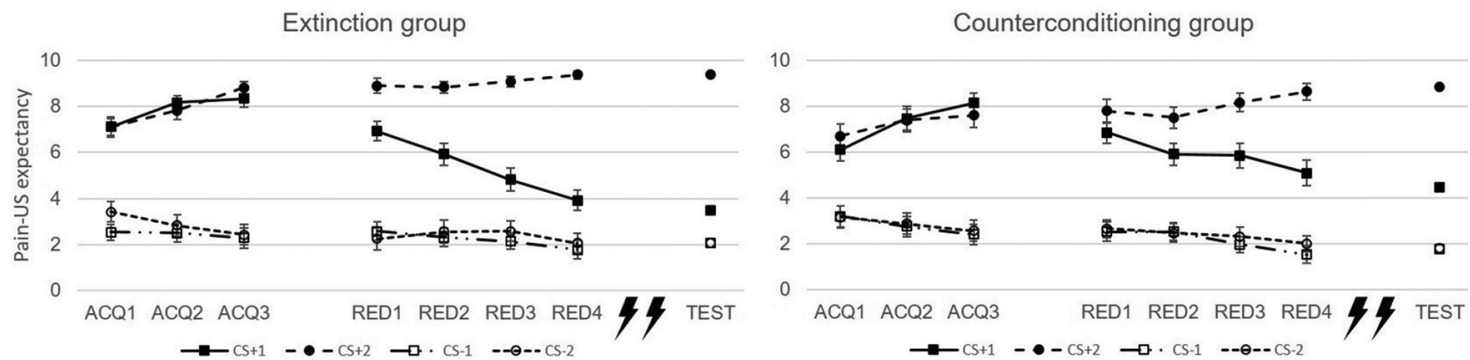

Note. Error bars denote standard errors. 
COUNTER: $\Delta_{(\mathrm{CS}+1}$ at ACQ3-CS+1 at RED4)-(CS-1 at ACQ3-CS-1 at RED4) $=1.7,95 \%$ CI $[.4,2.9], t(31)=2.75, p=.010$. There was a larger difference in fear ratings for the movement that was still paired with pain compared to its counterpart $\mathrm{CS}-$, but only in the

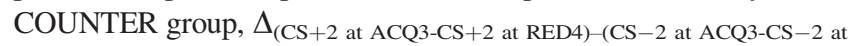
RED4) $=-1.8,95 \%$ CI $[-2.7,-.9], t(31)=-4.03, p<.001$. The same did not hold for the EXT group, $\Delta_{(\mathrm{CS}+2}$ at ACQ3-CS+2 at RED4)$(\mathrm{CS}-2$ at $\mathrm{ACQ} 3-\mathrm{CS}-2$ at RED4) $=-.8,95 \% \mathrm{CI}[-2.0, .4], t(35)=-1.35$, $p=.185$. Overall, the two groups reported a similar decrease in fear for the $\mathrm{CS}+{ }_{1}, \Delta_{\mathrm{EXT}(\mathrm{CS}+1 \text { at RED4-CS }+1 \text { at ACQ3)-COUNTER(CS }+1}$ at RED4-CS +1 at ACQ3) $=.7,95 \%$ CI $[-.8,2.1], t(66)=.91, p=.365$. Similar analyses showed that pain-US expectancy (Figure $3 \mathrm{~b}$ ) for $\mathrm{CS}+{ }_{1}$ was more reduced compared to $\mathrm{CS}+{ }_{2}$ in both the EXT group, $\Delta_{(\mathrm{CS}+1}$ at $\mathrm{ACQ} 3-\mathrm{CS}+1$ at $\left.\mathrm{RED} 4\right)-(\mathrm{CS}+2$ at $\mathrm{ACQ} 3-\mathrm{CS}+2$ at $\mathrm{RED} 4)=$ $5.0,95 \%$ CI $[3.8,6.1], t(35)=8.9, p<.001$, and the COUNTER group, $\Delta_{(\mathrm{CS}+1}$ at $\mathrm{ACQ} 3-\mathrm{CS}+1$ at $\left.\mathrm{RED} 4\right)-(\mathrm{CS}+2$ at ACQ3-CS+2 at $\mathrm{RED} 4)=$ $4.1,95 \%$ CI $[2.6,5.6], t(31)=5.6, p<.001$. In both groups, painUS expectancy for $\mathrm{CS}+{ }_{1}$ was more reduced compared to $\mathrm{CS}_{1}$, EXT: $\Delta_{(\mathrm{CS}+1}$ at $\mathrm{ACQ} 3-\mathrm{CS}+1$ at RED4)-(CS-1 at ACQ3-CS-1 at RED4) $=$ $3.9,95 \%$ CI $[2.6,5.3], t(35)=5.9, p<.001$; COUNTER: $\Delta_{(\mathrm{CS}+1}$ at $\mathrm{ACQ} 3-\mathrm{CS}+1$ at RED4)-(CS-1 at $\mathrm{ACQ} 3-\mathrm{CS}-1$ at RED4) $=2.2,95 \% \mathrm{CI}[.8$, 3.5], $t(31)=3.2, p=.003$. Again, there was a larger change in pain-US expectancy for the $\mathrm{CS}+{ }_{2}$ compared to the $\mathrm{CS}-{ }_{2}$ in the COUNTER group, $\Delta_{(\mathrm{CS}+2}$ at ACQ3-CS +2 at RED4)-(CS-2 at ACQ3-CS-2 at RED4) $=-1.6,95 \% \mathrm{CI}[-2.9,-.3], t(31)=-2.49, p=.019$, but not in the EXT group, $\Delta_{(\mathrm{CS}+2}$ at ACQ3-CS +2 at RED4)-(CS-2 at ACQ3$\mathrm{CS}-2$ at RED4) $=-.9,95 \% \mathrm{CI}[-2.1, .3], t(35)=-1.6, p=.123$. As above, the two groups reported a similar decrease in pain-US expectancy for the $\mathrm{CS}+{ }_{1}, \Delta_{\mathrm{EXT}(\mathrm{CS}+1 \text { at RED4-CS+1 at ACQ3)-COUNTER }}$ $(\mathrm{CS}+1$ at $\mathrm{RED} 4-\mathrm{CS}+1$ at $\mathrm{ACQ} 3)=1.4,95 \% \mathrm{CI}[-.2,3.0], t(66)=1.74$, $p=.087$. Taken together, these results demonstrate that both extinction and counterconditioning were effective in reducing fear of pain and pain-US expectancy, but to a similar degree.

\section{Comparing the Effect of Reinstatement Between Extinction and Counterconditioning}

\section{Does Counterconditioning Generate Less Return of Fear of Movement-Related Pain and Pain-US Expectancy Than Extinction?}

Figure 3 indicates that, contrary to our expectation, fear and pain-US expectancy ratings did not increase from the end of the fear reduction phase to test, for either of the two groups. Planned comparisons on fear of movement-related pain (Figure 3a) confirmed this visual impression. Specifically, they yielded no Group differences in return of fear for the $\mathrm{CS}+{ }_{1}, \Delta_{\mathrm{EXT}(\mathrm{CS}+1 \text { at TEST-CS }+1 \text { at }}$ RED4)- COUNTER(CS+1 at TEST-CS +1 at RED4) $=.05,95 \%$ CI $[-.7, .8], t(66)=.13, p=.894$, the $\mathrm{CS}+{ }_{2}, \Delta_{\mathrm{EXT}(\mathrm{CS}+2 \text { at TEST-CS }+2 \text { at }}$ RED4)-COUNTER(CS +2 at TEST-CS +2 at RED4) $=-.1,95 \%$ CI $[-.8, .5]$, $t(66)=-.46, p=.646$, the $\mathrm{CS}-{ }_{1}, \Delta_{\mathrm{EXT}(\mathrm{CS}-1 \text { at TEST-CS }-1 \text { at RED4) }}$ COUNTER(CS-1 at TEST-CS -1 at RED4) $=.07,95 \%$ CI $[-.7, .8], t(66)=$ $.18, p=.857$, or the $\mathrm{CS}-{ }_{2}, \Delta_{\mathrm{EXT}(\mathrm{CS}-2}$ at TEST-CS-2 at RED4)-COUNTER $(\mathrm{CS}-2$ at TEST-CS -2 at RED4) $=.4,95 \%$ CI $[-.3,1.2], t(66)=1.17, p=$ .246. Similar planned contrasts on pain-US expectancy (Figure 3b) showed that, in both groups, pain-US expectancies remained similar from the end of the fear reduction phase to test. This was the case for all stimuli, that is, for the $\mathrm{CS}+{ }_{1}, \Delta_{\mathrm{EXT}(\mathrm{CS}+1}$ at TEST-CS+1 at RED4)-
COUNTER $(\mathrm{CS}+1$ at TEST-CS +1 at RED4) $=.2,95 \%$ CI $[-.6,1.0], t(66)=$ $.51, p=.615$, the $\mathrm{CS}+{ }_{2}, \Delta_{\mathrm{EXT}(\mathrm{CS}+2 \text { at TEST-CS }+2 \text { at RED4)-COUNTER }}$ $(\mathrm{CS}+2$ at TEST-CS +2 at RED4) $=-.2,95 \% \mathrm{CI}[-.6, .2], t(66)=-.9$, $p=.362$, the $\mathrm{CS}-{ }_{1}, \Delta_{\mathrm{EXT}(\mathrm{CS}-1 \text { at TEST-CS }-1 \text { at RED4)-COUNTER(CS-1 at }}$ TEST-CS -1 at RED4) $=.1,95 \%$ CI $[-.7, .9], t(66)=.15, p=.883]$, as well as the CS- ${ }_{2}, \Delta_{\text {EXT(CS-2 at TEST-CS-2 at RED4)-COUNTER(CS-2 at }}$ TEST-CS-2 at RED4) $=.2,95 \%$ CI $[-.6,1.0], t(66)=.53, p=.597$. Taken together, these findings indicate that the reinstatement manipulation did not result in return of fear or pain-US expectancy for the CS that had been extinguished or counterconditioned, or for any other of the CSs, that is, that there was no differential fear reinstatement in either of the two groups.

\section{Does Counterconditioning Reduce CS Negative Valence More Than Extinction?}

Figure 4 shows a larger decrease in negative valence of the $\mathrm{CS}+{ }_{1}$ compared to the $\mathrm{CS}+{ }_{2}$ throughout the fear reduction phase. Planned contrasts showed that CS valence ratings decreased in a similar manner for the two groups. This was the case for all stimuli, that is, the $\mathrm{CS}+{ }_{1}, \Delta_{\mathrm{EXT}(\mathrm{CS}+1}$ at RED-CS +1 at $\left.\mathrm{ACQ}\right)$ COUNTER $(\mathrm{CS}+1$ at RED-CS +1 at ACQ $)=.05,95 \% \mathrm{CI}[-.5, .6], t(66)=.16$, $p=.870$, the $\mathrm{CS}+{ }_{2}, \Delta_{\mathrm{EXT}(\mathrm{CS}+2 \text { at RED-CS}+2 \text { at } \mathrm{ACQ})-\mathrm{COUNTER}(\mathrm{CS}+2 \text { at }}$ $\mathrm{RED}-\mathrm{CS}+2$ at $\mathrm{ACQ})=.4,95 \% \mathrm{CI}[.02, .9], t(66)=2.08, p=.042$ (but did not survive Bonferroni-Holm correction), the CS $-{ }_{1}, \Delta_{\mathrm{EXT}(\mathrm{CS}-1}$ at RED-CS -1 at ACQ)-COUNTER(CS -1 at RED-CS -1 at ACQ $=.1,95 \% \mathrm{CI}[-.3$, $.5], t(66)=.40, p=.688$, and the $\mathrm{CS}-{ }_{2}, \Delta_{\mathrm{EXT}(\mathrm{CS}-2}$ at RED-CS-2 at ACQ)- COUNTER(CS -2 at RED-CS -2 at ACQ $=.02,95 \%$ CI $[-.4, .4]$, $t(66)=.11, p=.913$. These results indicate that, contrary to our expectations, the affective valence of the counterconditioned CS+ did not decrease to a larger degree than that of the extinguished one.

\section{Discussion}

Fear of movement-related pain can be learned through classical conditioning, and is pivotal in the development and maintenance of chronic pain disability (Meulders, 2020; Vlaeyen, 2015). To reduce fear of movement-related pain, extinction-based protocols, such as exposure-in-vivo, are successfully applied to tackle chronic pain disability (den Hollander et al., 2010; Glombiewski et al., 2018). Exposure, however, is often followed by relapse (Bouton, 2002; Vervliet et al., 2013). Counterconditioning (i.e., pairing the fear-evoking CS with a positive US) has been suggested to reduce return of fear by virtue of its greater capacity to decrease CS negative valence (Dirikx et al., 2004; Hermans et al., 2002). We tested whether counterconditioning would lead to less return of fear of movement-related pain and a greater decrease in negative stimulus valence than extinction.

First, we replicated Meulders et al. (2015) in showing that counterconditioning and extinction were similarly effective in reducing fear of movement-related pain. Our study thus provides further evidence that counterconditioning can reduce conditioned fear of movement-related pain and pain-US expectancy. This finding is also in line with previous studies showing similar positive effects of counterconditioning in anxiety (Raes \& De Raedt, 2012) and disgust (Engelhard et al., 2014). Further, the observation that counterconditioning does not outperform extinction on immediate fear reduction is also in line with previous research (Meulders et al., 2015; Raes \& De Raedt, 2012). 
Figure 4

Retrospective Affective Valence Ratings for the CSs After Each Experimental Phase (ACQ, RED, and TEST), Separately Per Group

\section{CS valence}
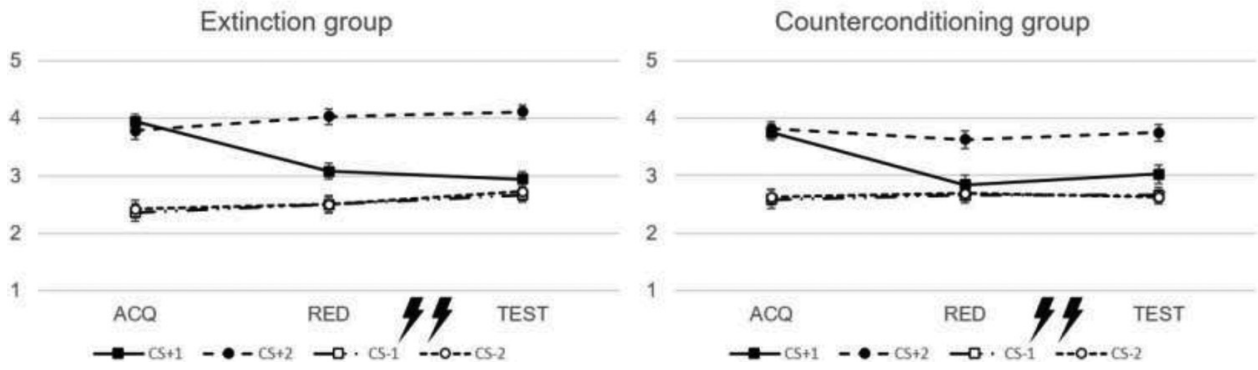

Note. Error bars denote standard errors.

In contrast to our expectations, participants in both groups did not show a return of differential fear of movement-related pain or pain-US expectancy at Test after the reinstatement manipulation. This is in contrast to the findings of a recent experiment showing that counterconditioning outperformed extinction by decreasing, though not entirely suppressing, spontaneous recovery and reinstatement of US-expectancy (Kang et al., 2018). Our findings, though, are more similar to those of van Dis et al. (2019), who also found the effect of counterconditioning and extinction on the return of fear to be of a similar magnitude.

The lack of reinstatement in the extinction Group is in contrast to previous studies that have successfully demonstrated reinstatement after extinction, using simpler variations of the VJM paradigm and smaller groups than in the present study (den Hollander et al., 2015; Meulders et al., 2015; Meulders \& Vlaeyen, 2013). The failure to observe reinstatement is also at odds with a large body of anxiety literature (e.g., Haaker et al., 2014; Kang et al., 2018) and may be explained by the increased complexity of our design. We used two CSs + and two CSs-, in contrast to most other studies using only one CS+ and one CS- (e.g., Haaker et al., 2014; Kang et al., 2018). As $\mathrm{CS}+{ }_{2}$ continued being associated with the pain-US throughout the fear reduction phase, it is likely that the context acquired some associative strength by virtue of mediated conditioning (cf. Ward-Robinson \& Hall, 1999). In that case, the reinstatement pain-USs may have been experienced as signaled by the context, thus likely being less surprising. Closely related is the clinically relevant procedure of occasionally reinforced extinction, in which occasional CS-US pairings or US-only presentations are included in the fear extinction phase, in order to decrease the differences between acquisition and extinction context and thus the corresponding context switch (Craske et al., 2014). The reduced context switch between acquisition and extinction is expected to facilitate retrieval of the extinction memory (Bouton, 2002). Compared to regular extinction procedures, occasionally reinforced extinction leads to less return of fear (Thompson et al., 2018). In addition to the context, $\mathrm{CS}+{ }_{2}$, which continued being associated with the pain-US throughout the fear reduction phase, may have also been considered a reliable predictor of the pain-US, thus attenuating the expected reinstatement effect (Rescorla \& Cunningham, 1977). As both the context and the $\mathrm{CS}+{ }_{2}$ may have come to signal the pain-US, these two explanations are not mutually exclusive.

We also did not find that the negative valence of the counterconditioned $\mathrm{CS}+$ was more reduced than that of the extinguished $\mathrm{CS}+$. This is in contrast to previous research (Engelhard et al., 2014) and theoretical accounts proposing that counterconditioning relies on changing the negative stimulus valence (Hermans et al., 2002). Interestingly, however, evidence is accumulating that counterconditioning may reduce fear and US-expectancy without actually changing CS valence (Kang et al., 2018; Meulders et al., 2015). These findings likely suggest that the underlying mechanism of counterconditioning might be at least partly different than initially thought. For example, Dunsmoor and colleagues (2015) demonstrated that pairing the $\mathrm{CS}+$ with a novel, neutral (rather than opposite valenced) outcome ("novelty-facilitated extinction") was superior to regular extinction in reducing spontaneous fear recovery. According to these authors, pairing the CS+ with a surprising though mundane outcome is a more unambiguous sign of change than the mere omission of the initial (threat) US, and may thus facilitate inhibitory learning by increasing prediction error. In support of this, Raes and De Raedt (2012) also showed that counterconditioning with a positive or a neutral outcome had similar effects in subsequent implicit measurements of $\mathrm{CS}+$ valence. On a similar note, US-devaluation techniques, which are assumed to decrease stimulus valence, were shown not to outperform traditional extinction in decreasing conditioned fear (Dibbets et al., 2018) and its return (Landkroon et al., 2020). Taken together, these findings indicate that additional or alternative processes than changing the affective valence of the CS+ may actually underlie counterconditioning. These processes likely relate to the maximization of expectancy violation (Craske et al., 2014; Keller et al., 2020).

The present study and hypotheses were designed from the perspective of the inhibitory learning model of extinction (Bouton, 2002). Propositional (Mitchell et al., 2009) and goal-directed (Boddez et al., 2020) models, however, would predict that interventions providing more information about the feared CS would be more effective at reducing the return of fear compared to counterconditioning. For example, demonstrating that more threatening CSs are not followed by the pain-US is expected to lead one to infer that the same would apply to less threatening CSs as well (cf. 
Mertens et al., 2019; Preusser et al., 2017). Given that counterconditioning is not consistently found to be more effective than extinction in reducing the return of fear (Kang et al., 2018; van Dis et al., 2019), these emerging theoretical perspectives offer valuable alternatives for research.

Our reward manipulation entailed increasing the probability to win a future lottery prize rather than obtaining a reward with certainty. This reward manipulation has been used successfully in healthy student samples before. Specifically, Claes et al. (2016) reported moderate to high lottery ticket value, ticket pleasantness, and importance of obtaining tickets. Furthermore, our findings are in line with these of Meulders et al. (2015), who provided a reward with certainty (a $€$ symbol on the computer screen representing an additional profit of $€ .50$ each time it appeared), but also found no differences in fear reduction after extinction or counterconditioning. We are thus fairly confident that our (lack of) findings is not due to the way we manipulated reward.

The present study had some limitations. First, technical problems prevented us from obtaining reliable eyeblink startle reflex measurements. Nevertheless, self-reported measures of fear such as these that we relied on are considered valid (Boddez et al., 2013). Similarly, we assessed stimulus valence by means of verbal ratings, but implicit measures (e.g., affective priming tasks; Engelhard et al., 2014) may yield different results. Second, our sample consisted of healthy volunteers, who received experimentally induced pain. Replication is thus warranted before findings are generalized to clinical populations. Third, our study was adequately powered to detect only medium-to-large effects, raising the possibility that smaller effects may have been missed. However, the reinstatement effect is routinely demonstrated with smaller samples and simpler designs (for an elaborate review, see Haaker et al., 2014; for simpler variations of the VJM paradigm, see den Hollander et al., 2015; Meulders et al., 2015; Meulders \& Vlaeyen, 2013), attesting to the complexity of our design as the primary plausible explanation for the lack of reinstatement effects.

A strength of this study is the use of a complex design with two CSs+, only one of which was later extinguished or counterconditioned, and two CSs-. This deviates from classic differential paradigms on counterconditioning (e.g., Engelhard et al., 2014; Kang et al., 2018; Raes \& De Raedt, 2012) and human fear reinstatement (Haaker et al., 2014), which most often only use one $\mathrm{CS}+$ and one CS-. Importantly, by using this design we did not replicate the well-established reinstatement effect that has been demonstrated repeatedly with one (extinguished) $\mathrm{CS}+$ and one CS - joystick movement (Meulders, 2020). Our findings raise the issue of balancing experimental control and modeling real-life complexity more adequately in experimental paradigms and how this balance may affect findings. Similar suggestions have recently been made for the advancement of other experimental paradigms (e.g., for extinction; Scheveneels et al., 2016).

To conclude, we showed that counterconditioning is as effective as extinction in reducing pain-related fear but does not seem to outperform extinction when it comes to reducing the return of fear or the negative valence of the conditioned stimulus. The complexity of study designs should be considered.

\section{References}

Boddez, Y., Baeyens, F., Luyten, L., Vansteenwegen, D., Hermans, D., \& Beckers, T. (2013). Rating data are underrated: Validity of U.S. expectancy in human fear conditioning. Journal of Behavior Therapy and Experimental Psychiatry, 44(2), 201-206. 10.1016/j.jbtep.2012.08.003

Boddez, Y., Moors, A., Mertens, G., \& De Houwer, J. (2020). Tackling fear: Beyond associative memory activation as the only determinant of fear responding. Neuroscience and Biobehavioral Reviews, 112, 410-419. 10.1016/j.neubiorev.2020.02.009

Bouton, M. E. (2002). Context, ambiguity, and unlearning: Sources of relapse after behavioral extinction. Biological Psychiatry, 52(10), 976-986. 10.1016/S0006-3223(02)01546-9

Bradley, M., \& Lang, P. J. (1994). Measuring Emotion. The Self-Assessment Manikin and the semantic differential. Journal of Behavior Therapy and Experimental Psychiatry, 25(1), 49-59. 10.1016/0005-7916(94) 90063-9

Claes, N., Crombez, G., Meulders, A., \& Vlaeyen, J. W. S. (2016). Between the devil and the deep blue sea: Avoidance-avoidance competition increases pain-related fear and slows decision-making. The Journal of Pain, 17(4), 424-435. 10.1016/j.jpain.2015.12.005

Claes, N., Crombez, G., \& Vlaeyen, J. W. S. (2015). Pain-avoidance versus reward-seeking: An experimental investigation. Pain, 156(8), 1449-1457. 10.1097/j.pain.0000000000000116

Craske, M. G., Treanor, M., Conway, C. C., Zbozinek, T., \& Vervliet, B. (2014). Maximizing exposure therapy: An inhibitory learning approach. Behaviour Research and Therapy, 58, 10-23. 10.1016/j. brat.2014.04.006

den Hollander, M., De Jong, J. R., Volders, S., Goossens, M. E. J. B., Smeets, R. J. E. M., \& Vlaeyen, J. W. S. (2010). Fear reduction in patients with chronic pain: A learning theory perspective. Expert Review of Neurotherapeutics, 10(11), 1733-1745. 10.1586/ern.10.115

den Hollander, M., Meulders, A., Jakobs, M., \& Vlaeyen, J. W. S. (2015). The effect of threat information on acquisition, extinction, and reinstatement of experimentally conditioned fear of movement-related pain. Pain Medicine, 16(12), 2302-2315. 10.1111/pme.12836

Dibbets, P., Lemmens, A., \& Voncken, M. (2018). Turning negative memories around: Contingency versus devaluation techniques. Journal of Behavior Therapy and Experimental Psychiatry, 60, 5-12. 10.1016/j. jbtep.2018.02.001

Dirikx, T., Hermans, D., Vansteenwegen, D., Baeyens, F., \& Eelen, P. (2004). Reinstatement of extinguished conditioned responses and negative stimulus valence as a pathway to return of fear in humans. Learning \& Memory, 11(5), 549-554. 10.1101/lm.78004

Dunsmoor, J. E., Campese, V. D., Ceceli, A. O., LeDoux, J. E., \& Phelps, E. A. (2015). Novelty-facilitated extinction: Providing a novel outcome in place of an expected threat diminishes recovery of defensive responses. Biological Psychiatry, 78(3), 203-209. 10.1016/j.biopsych.2014.12.008

Engelen, U., De Peuter, S., Victoir, A., Van Diest, I., \& Van Den Bergh, O. (2006). Verdere validering van de Positive and Negative Affect Schedule (PANAS) en vergelijking van twee Nederlandstalige versies [Further validation of the Positive and Negative Affect Schedule (PANAS) and comparison of two Dutch versions]. Gedrag en Gezondheid, 34(2), 89-102. 10.1007/BF03087979

Engelhard, I. M., Leer, A., Lange, E., \& Olatunji, B. O. (2014). Shaking that icky feeling: Effects of extinction and counterconditioning on disgust-related evaluative learning. Behavior Therapy, 45(5), 708-719. 10.1016/j.beth.2014.04.003

Faul, F., Erdfelder, E., Lang, A.-G., \& Buchner, A. (2007). G*Power 3: A flexible statistical power analysis program for the social, behavioral, and biomedical sciences. Behavior Research Methods, 39(2), 175-191. $10.3758 / \mathrm{bf} 03193146$

Glombiewski, J. A., Holzapfel, S., Riecke, J., Vlaeyen, J. W. S., de Jong, J., Lemmer, G., \& Rief, W. (2018). Exposure and CBT for chronic back pain: An RCT on differential efficacy and optimal length of treatment. 
Journal of Consulting and Clinical Psychology, 86(6), 533-545. 10.1037/ccp0000298

Haaker, J., Golkar, A., Hermans, D., \& Lonsdorf, T. B. (2014). A review on human reinstatement studies: An overview and methodological challenges. Learning \& Memory, 21(9), 424-440. 10.1101/lm.036053.114

Hermans, D., Vansteenwegen, D., Crombez, G., Baeyens, F., \& Eelen, P. (2002). Expectancy-learning and evaluative learning in human classical conditioning: Affective priming as an indirect and unobtrusive measure of conditioned stimulus valence. Behaviour Research and Therapy, 40(3), 217-234. 10.1016/S0005-7967(01)00006-7

Kang, S., Vervliet, B., Engelhard, I. M., van Dis, E. A. M., \& Hagenaars, M. A. (2018). Reduced return of threat expectancy after counterconditioning verus extinction. Behaviour Research and Therapy, 108, 78-84. 10.1016/j.brat.2018.06.009

Keller, N. E., Hennings, A. C., \& Dunsmoor, J. E. (2020). Behavioral and neural processes in counterconditioning: Past and future directions. Behaviour Research and Therapy, 125, 103532. 10.1016/j. brat.2019.103532

Landkroon, E., Mertens, G., \& Engelhard, I. M. (2020). Devaluation of threat memory using a dual-task intervention does not reduce context renewal of fear. Behaviour Research and Therapy, 124, 103480. 10.1016/j.brat.2019.103480

LimeSurvey Project Team \& Schmitz, C. (2012). LimeSurvey: An open source survey tool. http://www.limesurvey.org

McNeil, D. W., \& Rainwater, A. J. (1998). Development of the Fear of Pain Questionnaire-III. Journal of Behavioral Medicine, 21(4), 389-410. 10.1023/a:1018782831217

Mertens, G., Leer, A., van Dis, E. A. M., Vermeer, L., Steenhuizen, A., van der Veen, L., \& Engelhard, I. M. (2019). Secondary extinction reduces reinstatement of threat expectancy and conditioned skin conductance responses in human fear conditioning. Journal of Behavior Therapy and Experimental Psychiatry, 62, 103-111. 10.1016/j. jbtep.2018.09.007

Meulders, A. (2020). Fear in the context of pain: Lessons learned from 100 years of fear conditioning research. Behaviour Research and Therapy, 131, 103635. 10.1016/j.brat.2020.103635

Meulders, A., Karsdorp, P. A., Claes, N., \& Vlaeyen, J. W. S. (2015). Comparing counterconditioning and extinction as methods to reduce fear of movement-related pain. The Journal of Pain, 16(12), 1353-1365. 10.1016/j.jpain.2015.09.007

Meulders, A., Rousseau, A., \& Vlaeyen, J. W. S. (2015). Motor intention as a trigger for fear of movement-related pain: An experimental cross-US reinstatement study. Journal of Experimental Psychopathology, 6(3), 206-228. 10.5127/jep.043614

Meulders, A., \& Vlaeyen, J. W. S. (2013). Mere intention to perform painful movements elicits fear of movement-related pain: An experimental study on fear acquisition beyond actual movements. The Journal of Pain, 14(4), 412-423. 10.1016/j.jpain.2012.12.014

Mitchell, C. J., De Houwer, J., \& Lovibond, P. F. (2009). The propositional nature of human associative learning. Behavioral and Brain Sciences, 32(2), 183-198. 10.1017/S0140525X09001149

Preusser, F., Margraf, J., \& Zlomuzica, A. (2017). Generalization of extinguished fear to untreated fear stimuli after exposure. Neuropsychopharmacology, 42(13), 2545-2552. 10.1038/npp.2017.119
Raes, A. K., \& De Raedt, R. (2012). The effect of counterconditioning on evaluative responses and harm expectancy in a fear conditioning paradigm. Behavior Therapy, 43(4), 757-767. 10.1016/j.beth.2012.03.012

Rescorla, R. A., \& Cunningham, C. L. (1977). The erasure of reinstated fear. Animal Learning \& Behavior, 5(4), 386-394. 10.3758/ BF03209584

Roelofs, J., Peters, M. L., Deutz, J., Spijker, C., \& Vlaeyen, J. W. S. (2005). The Fear of Pain Questionnaire (FPQ): Further psychometric examination in a non-clinical sample. Pain, 116(3), 339-346. 10.1016/j. pain.2005.05.003

Scheveneels, S., Boddez, Y., Vervliet, B., \& Hermans, D. (2016). The validity of laboratory-based treatment research: Bridging the gap between fear extinction and exposure treatment. Behaviour Research and Therapy, 86, 87-94. 10.1016/j.brat.2016.08.015

Spielberger, C. (1983). Manual for the state-trait anxiety inventory (STAIForm Y). Consulting Psychology Press.

Sullivan, M. J. L., Bishop, S. R. S., \& Pivik, J. (1995). The Pain Catastrophizing Scale: Development and validation. Psychological Assessment, 7(4), 524-532. 10.1037/1040-3590.7.4.524

Thompson, A., McEvoy, P. M., \& Lipp, O. V. (2018). Enhancing extinction learning: Occasional presentations of the unconditioned stimulus during extinction eliminate spontaneous recovery, but not necessarily reacquisition of fear. Behaviour Research and Therapy, 108, 29-39. 10.1016/j.brat.2018.07.001

Van Damme, S., Crombez, G., Bijttebier, P., Goubert, L., \& Van Houdenhove, B. (2002). A confirmatory factor analysis of the Pain Catastrophizing Scale. Invariant factor structure across clinical and non-clinical populations. Pain, 96(3), 319-324. 10.1016/s0304-3959(01)00463-8

Van der Ploeg, H. M. (1980). Validity of the Zelf-Beoordelings-Vragenlijst [A Dutch version of the Spielberger State-Trait Anxiety Inventory] Nederlands Tijdschrift Voor de Psychologie en Haar Grensgebieden, 35(4), 243-249.

van Dis, E. A. M., Hagenaars, M. A., Bockting, C. L. H., \& Engelhard, I. M. (2019). Reducing negative stimulus valence does not attenuate the return of fear: Two counterconditioning experiments. Behaviour Research and Therapy, 120, 103416. 10.1016/j.brat.2019.103416

Vervliet, B., Craske, M. G., \& Hermans, D. (2013). Fear extinction and relapse: State of the art. Annual Review of Clinical Psychology, 9(1), 215-248. 10.1146/annurev-clinpsy-050212-185542

Vlaeyen, J. W. S. (2015). Learning to predict and control harmful events: Chronic pain and conditioning. Pain, 156(4), S86-S93. 10.1097/j. pain. 0000000000000107

Ward-Robinson, J., \& Hall, G. (1999). The role of mediated conditioning in acquired equivalence. The Quarterly Journal of Experimental Psychology, 52(4), 335-350. 10.1080/713932712

Watson, D., Clark, L. A., \& Tellegen, A. (1988). Development and validation of brief measures of positive and negative affect: The PANAS scales. Journal of Personality and Social Psychology, 54(6), 1063-1070. 10.1037/0022-3514.54.6.1063

Received June 23, 2020

Revision received October 21, 2020

Accepted December 14, 2020 